\title{
Viabilidade econômico-financeira do confinamento de ovinos alimentados com rações contendo torta de mamona
}

\author{
Economic and financial feasibility of feedlot sheep fed with rations containing castor cake \\ Fernando Henrique Teixeira Gomes ${ }^{1^{\star}}$, Magno José Duarte Cândido ${ }^{2}$, Maria Socorro de Souza \\ Carneiro $^{2}$, Rafael Nogueira Furtado ${ }^{2}$, Elzânia Sales Pereira² ${ }^{2}$, Dilermando Miranda da Fonseca ${ }^{3}$, \\ Roberto Cláudio Fernandes Franco Pompeu ${ }^{4} \&$ Weberte Alan Sombra ${ }^{5}$ \\ ${ }^{1}$ Superintendência Federal de Agricultura, Fortaleza, Ceará, Brasil. *Autor para correspondência: fernandohtg@gmail.com. \\ ${ }^{2}$ Universidade Federal do Ceará, Fortaleza, Ceará, Brasil. \\ ${ }^{3}$ Universidade Federal de Viçosa, Viçosa, Minas Gerais, Brasil. \\ ${ }^{4}$ Empresa Brasileira de Pesquisa Agropecuária, Sobral, Ceará, Brasil. \\ ${ }^{5}$ Instituto Federal de Educação, Ciência e Tecnologia do Ceará, Tauá, Ceará, Brasil.
}

Submissão: 24/10/2016 / Aceite: 13/06/2018

\begin{abstract}
RESUMO
Objetivou-se avaliar o desempenho e a resposta econômica de 20 ovinos distribuídos em delineamento em blocos ao acaso e submetidos a um de cinco tratamentos testando a torta de mamona como ingrediente em rações (torta de mamona não tratada, tratada com calcário calcítico, ureia, fosfato monobicálcico e autoclavada). O volumoso foi feno de capim-tifton 85. Foram considerados os preços de mercado de ingredientes das rações, peso corporal (PC) e peso da carcaça, buscando-se determinar condições mínimas para tornar o empreendimento economicamente viável. De posse do custo de cada ração e do consumo de matéria seca, foram analisados indicadores técnicos, zootécnicos e econômicos utilizando-se o programa Excel ${ }^{\circledR}$. A produção diária (kg PC e kg carcaça) foi maior para ovinos consumindo rações contendo torta de mamona autoclavada e tratada com fosfato monobicálcico, apresentando maior rotatividade do sistema de produção, resultando em maior número de animais terminados anualmente. Esses sistemas de produção obtiveram maior renda bruta. A compra de animais e alimentação foram os itens mais representativos nas despesas de custeio para produção de PC, representando 44,8 e 43,3\%/ano em média, respectivamente. Considerando um preço de venda de $R \$$ 4,70/kg PC e R $\$ 13,40 / \mathrm{kg}$ de carcaça, o sistema de produção com torta tratada com fosfato monobicálcico apresentou melhor resposta econômica, com relação benefício/custo de 1,07, valor presente líquido (VPL) de $R \$ 73.117,34$, taxa interna de retorno (TIR) de 54\% e custo total de $R \$ 4,32 / \mathrm{kg} P C$. Por outro lado, 0 sistema utilizando torta não tratada como ingrediente apresentou relação benefício/custo de 1,00, VPL de $1.772,62$, TIR de $8 \%$ e custo total de $R \$ 4,63 / \mathrm{kg}$ PC, sem indícios de intoxicação dos animais. Concluiu-se que a torta de mamona tratada com fosfato monobicálcico é promissora para uso em rações de ovinos.
\end{abstract}

PALAVRAS-CHAVE: custo de produção, ovino, Ricinus communis.

\begin{abstract}
Twenty sheep were placed in a completely randomized block design and submitted to one of five treatments testing castor cake as a ration ingredient (untreated castor cake, treated with limestone, with urea, with mono-dicalcium phosphate and autoclaved) to evaluate their performance and the economic output. The roughage consisted of tifton-85 bermudagrass hay. The market prices of the rations ingredients, body weight (BW) and the carcass weight were considered to identify the minimum conditions for the enterprise to become economically feasible. After obtaining the ration cost and the dry matter intake, the technical, zootechnical and economic indexes were analyzed using the Excel ${ }^{\circledR}$ program. The daily production ( $\mathrm{kg}$ of BW or $\mathrm{kg}$ of carcass) was higher for sheep eating rations with autoclaved castor cake and treated with mono-dicalcium phosphate, showing the highest production system turnover and providing the highest number of finished animals on a yearly basis. These production systems showed the highest gross income. The animal purchase and feeding were the most representative items on BW production expenses, representing 44.8 and $43.3 \% /$ year on average, respectively. Adopting $R \$ 4.70 / \mathrm{kg}$ BW and $R \$ 13.40 / \mathrm{kg}$ carcass as sell prices, the production system containing castor cake treated with mono-dicalcium phosphate showed the best economic output, with a 1.07 benefit/cost, a $R \$ 73,117.34$ liquid present value (LPV), 54\% internal return rate (IRR) and a $\mathrm{R} \$ 4.32 \mathrm{BW}$ total cost. On the other hand, the production system using non-treated cake as the ingredient showed a 1.00 benefit/cost, $R \$ 1,772.62$
\end{abstract}


LPV, $8 \%$ IRR and R $\$ 4.63 / \mathrm{kg}$ BW total cost, without any evidence of animal toxicity. It can be concluded that mono-dicalcium phosphate-treated castor cake is a promising ingredient to be used in sheep rations.

KEYWORDS: production cost, sheep, Ricinus communis.

\section{INTRODUÇÃO}

A ovinocultura é uma atividade de notável importância econômica e social no nordeste brasileiro, principalmente na sua porção semiárida, caracterizada predominantemente por sistemas de produção extensivos visando à produção de carne e pele, sendo influenciados negativamente nas épocas secas, quando a produção de forragem é baixa e os animais apresentam baixo desempenho produtivo. Uma estratégia utilizada para a melhoria do desempenho dos rebanhos nordestinos de pequenos ruminantes, caracterizados por baixos índices produtivos, seria o manejo alimentar adequado, principalmente nas épocas de escassez de forragens, usando-se sistemas intensivos de produção, como o confinamento ou semiconfinamento. Surge, então, a necessidade de estudar a viabilidade de incluir fontes alimentares alternativas e quantificar a resposta animal em termos produtivos e econômicos (CUNHA et al. 2008).

Um subproduto com potencial para inclusão na alimentação animal é a torta de mamona, que possui significativo teor de proteína bruta e apresenta disponibilidade em diversas regiões do nordeste brasileiro. Entretanto, um empecilho para a utilização da torta de mamona é a presença da ricina, proteína tóxica localizada no endosperma da semente. ANANDAN et al. (2005), estudando métodos de destoxificação da torta de mamona, verificaram que a ricina foi $100 \%$ eliminada quando autoclavada (15 psi $/ 60 \mathrm{~min}$.) ou tratada com solução de hidróxido de cálcio (40 g/kg torta de mamona). ASLANI et al. (2007) verificaram a intoxicação de ovinos por ingestão da semente de mamona, enquanto OLIVEIRA et al. (2010) não observaram sintomas clínicos de intoxicação de ruminantes ingerindo rações com torta ou farelo de mamona não tratada com métodos de destoxificação.

A utilização de métodos alternativos de destoxificação da torta de mamona deve ser estudada sob o ponto de vista biológico e econômico, auxiliando o criador na tomada de decisão acerca da destoxificação da torta de mamona incluída na alimentação dos ovinos. Ressalta-se que os estudos sobre análise econômica da ovinocultura são escassos e, na maioria das vezes, apresentam-se incompletos. São muito importantes, porém, para que se avalie melhor a atividade e seja possível reduzir custos, aumentar produtividade e estabelecer metas com o objetivo de atingir alta lucratividade com eficiência e sustentabilidade do negócio (BARROS et al. 2009).

Nesse contexto, objetivou-se avaliar o desempenho e a resposta econômico-financeira de ovinos alimentados com rações contendo torta de mamona submetida ou não a diferentes métodos de destoxificação.

\section{MATERIAL E MÉTODOS}

O experimento foi conduzido em Fortaleza, Ceará, Brasil, situada na zona litorânea a 15,49 m de altitude, $3^{\circ} 43^{\prime} 02^{\prime \prime}$ de latitude sul e $38^{\circ} 32^{\prime} 35^{\prime \prime}$ de longitude oeste, durante o período compreendido de março a agosto de 2009. A torta de mamona foi obtida a partir da extração mecânica do óleo da semente (90 a 110 $\left.{ }^{\circ} \mathrm{C}\right)$ em Quixeramobim - Ceará. Foram utilizados 20 ovinos ( $1 / 2$ Morada Nova variedade Vermelha x $1 / 2$ sem padrão racial definido), sendo 10 machos inteiros e 10 fêmeas, com peso médio inicial de $18,7 \pm 1,18 \mathrm{~kg}$ e 240 dias de idade. Os animais foram vermifugados, suplementados com vitaminas A, D e E, sendo confinados em baias individuais de $1,0 \mathrm{~m}^{2}$, providas de comedouros e bebedouros.

A escolha dos métodos de destoxificação da torta de mamona que constituíram os tratamentos foi realizada com base em eletroforese em gel de poliacrilamida (FURTADO et al. 2012), considerando como mais eficientes os agentes que promoveram maior desaparecimento das subunidades da ricina. Os cinco tratamentos foram: torta de mamona não tratada (controle), torta de mamona tratada com calcário calcítico, torta de mamona tratada com ureia, torta de mamona tratada com fosfato monobicálcico e torta de mamona autoclavada, num delineamento em blocos ao acaso com quatro repetições (ovinos), formando dois blocos em função do sexo dos animais. O tratamento da torta de mamona (TM) foi realizado pela diluição do agente químico na água nas seguintes proporções: $60 \mathrm{~g}$ de calcário calcítico/500 mL água/kg TM; $60 \mathrm{~g}$ de fosfato monobicálcico/500 mL água/kg TM; e $10 \mathrm{~g}$ de ureia/500 mL água/kg TM. Com os produtos diluídos, a torta foi tratada homogeneamente, aplicando-se com auxílio de baldes, e revolvendo a massa com pás. Posteriormente, foram mantidas em tambores, por oito horas (à noite), as tortas tratadas com calcário calcítico ou com fosfato monobicálcico, e por sete dias, a torta tratada com ureia. Finalmente, a torta tratada foi exposta ao sol, sobre lonas, até a secagem ( $90 \%$ de matéria seca). Esse procedimento usado para 
tratamento da torta de mamona e sua autoclavagem (15 psi a $123{ }^{\circ} \mathrm{C}$, por 60 min.) foram baseados em ANANDAN et al. (2005). Durante a diluição do agente químico, foi realizada a medição do pH na solução, com auxílio de potenciômetro digital, obtendo-se: calcário calcítico, 7; ureia, 7; e fosfato monobicálcico, 4.

As rações experimentais foram formuladas conforme NRC (2007), utilizando relação volumoso:concentrado de 50:50. As rações foram fornecidas duas vezes ao dia, $50 \%$ às $8 \mathrm{~h}$ e $50 \%$ às $16 \mathrm{~h}$, sendo coletadas sobras, no dia seguinte, para determinação do consumo diário e controle do nível de sobras, mantendo de 15 a 20\%. Na Tabela 1 encontra-se a composição centesimal da ração, preço dos ingredientes e preço do concentrado.

Tabela 1. Proporção e preço dos ingredientes em rações contendo torta de mamona submetida a métodos de destoxificação.

Table 1. Proportion and price of ingredients in rations containing castor cake submitted to detoxification methods.

\begin{tabular}{|c|c|c|c|c|c|c|}
\hline \multirow{2}{*}{ Componente $^{1}$} & \multirow[b]{2}{*}{$\mathrm{R} \$ / \mathrm{kg} \mathrm{MN}$} & \multicolumn{5}{|c|}{ Método de destoxificação² } \\
\hline & & NT & $\mathrm{cc}$ & UR & FOS & $\mathrm{ACL}$ \\
\hline Feno de capim-tifton 85 & 0,42 & 49,31 & 49,54 & 49,54 & 49,42 & 48,68 \\
\hline Fubá de milho & 0,80 & 34,47 & 34,51 & 34,31 & 34,36 & 34,90 \\
\hline TM não tratada & 0,20 & 8,11 & 0 & 0 & 0 & 0 \\
\hline TM tratada com C & 0,21 & 0 & 8,11 & 0 & 0 & 0 \\
\hline TM tratada com ureia & 0,21 & 0 & 0 & 8,07 & 0 & 0 \\
\hline TM tratada com FM & 0,29 & 0 & 0 & 0 & 8,08 & 0 \\
\hline TM autoclavada ${ }^{3}$ & 0,23 & 0 & 0 & 0 & 0 & 8,21 \\
\hline Farelo de soja & 0,80 & 4,05 & 4,07 & 4,04 & 4,04 & 4,10 \\
\hline Farelo de trigo & 0,40 & 2,79 & 2,78 & 2,78 & 2,78 & 2,82 \\
\hline Sal mineral ${ }^{4}$ & 1,07 & 0,507 & 0,508 & 0,505 & 0,505 & 0,513 \\
\hline Calcário calcítico & 0,15 & 0,283 & 0 & 0,282 & 0,334 & 0,286 \\
\hline Ureia & 1,10 & 0,253 & 0,253 & 0,252 & 0,253 & 0,257 \\
\hline Sal comum $(\mathrm{NaCl})$ & 0,40 & 0,203 & 0,203 & 0,202 & 0,202 & 0,205 \\
\hline Sulfato de amônio & 0,70 & 0,025 & 0,025 & 0,025 & 0,025 & 0,025 \\
\hline Concentrado $(\mathrm{R} \$ / \mathrm{kg})$ & - & 0,681 & 0,685 & 0,683 & 0,695 & 0,686 \\
\hline
\end{tabular}

${ }^{1} \mathrm{TM}$ = torta de mamona; C = calcário calcítico; FM = fosfato monobicálcico; ${ }^{2} \mathrm{NT}$ = ração contendo torta de mamona não tratada; CC $=$ ração contendo torta de mamona tratada com calcário calcítico; UR = ração contendo torta de mamona tratada com ureia; FOS = ração contendo torta de mamona tratada com fosfato monobicálcico; $A C L$ = ração contendo torta de mamona autoclavada; ${ }^{3} \mathrm{Preço}$ inclui apenas gastos com energia elétrica; ${ }^{4}$ Composição: fosfato, $65,0 \mathrm{~g}$; cálcio, 160,0g; enxofre, 15,0 g; magnésio, 6,5 g; sódio, 150,0 g; cobalto, 0,125 g; zinco, 4,5 g; ferro, $1,7 \mathrm{~g}$; manganês, 4,5 g; iodo, 0,06 g; selênio, 0,03 g; flúor, 0,95 g; veículo, $1000 \mathrm{~g}$.

O período experimental foi de 70 dias, subdividido em 14 dias de adaptação e 56 dias de coleta de dados, sendo realizadas pesagens dos animais ao início e ao término do período de coleta de dados. A fim de se obter o coeficiente de perdas ao jejum médio para cada ovino, também foi realizada uma pesagem dos animais ao fim da tarde (alimentados normalmente) e no dia seguinte pela manhã após jejum de sólidos e líquidos de 16 horas. Foram realizadas coletas semanais de $10 \%$ da ração ofertada e das sobras, armazenadas a $-10 \stackrel{\circ}{ } \mathrm{C}$, e realizada ao término do experimento uma amostra composta/animal•tratamento, para a realização das análises de matéria seca (AOAC, 1990) no Laboratório de Nutrição Animal da Universidade Federal do Ceará.

Ao atingir o fim do período experimental, os animais foram abatidos, após insensibilização por atordoamento, na região atlanto-occipital, seguida de sangria por cerca de quatro minutos. Posteriormente, foi realizada a evisceração, esfola e separação dos componentes corporais. Então, as carcaças foram pesadas, acondicionadas em sacos plásticos, resfriadas por 24 horas a $5^{\circ} \mathrm{C}$, em câmara frigorífica, e, decorrido esse tempo, foram pesadas para a obtenção do peso da carcaça fria.

Foi determinado o ganho de peso total e a eficiência alimentar, sendo esses dados submetidos à análise de variância e teste de comparação de médias (Tukey, $p<0,05$ ), com auxílio do procedimento GLM do programa computacional SAS (SAS INSTITUTE, 2003).

Para a análise econômico-financeira dos animais vendidos por $\mathrm{kg}$ de peso corporal (PC), foi considerada a terminação de animais com PC inicial de $18 \mathrm{~kg}$. Com base no ganho médio diário, estimou-se o número de dias para os animais chegarem a $30 \mathrm{~kg}$ de PC. O número de lotes terminados por ano foi 
estimado pela divisão do número de dias de um ano (365) pela soma do número de dias de confinamento para o animal ganhar $12 \mathrm{~kg}$ com o período de vazio sanitário (sete dias). Para a obtenção dos índices econômicos para a venda por $\mathrm{kg}$ de carcaça, foram considerados ainda o peso da carcaça fria (PCF) e o rendimento da carcaça fria (RCF) obtidos no experimento, sendo: $R C F=(P C F / P C A J) \times 100$, onde PCAJ é o peso corporal ao abate. A projeção para cada um dos cinco tratamentos (sistemas) foi realizada considerando a terminação de um lote de 250 animais.

Para o cálculo do custo do feno de capim-tifton 85 , considerou-se que este foi produzido na própria propriedade, de acordo com CÂNDIDO et al. (2008), resultando em custo de $R \$ 0,42 / \mathrm{kg}$ de feno. Para os cálculos do custo do concentrado, foram considerados preços de mercado dos ingredientes da ração dos animais (Tabela 1). Para o cálculo do preço da torta de mamona destoxificada, foi orçado na região o preço do agente químico para tratamento da torta e, no caso da autoclavagem, os gastos com energia elétrica. A partir dos dados de consumo de MS, desempenho dos animais e custo da ração, foram analisados indicadores técnicos, zootécnicos e econômicos com o auxílio de planilhas do Programa Excel ${ }^{\circledR}$.

Para estimar a área para esta atividade, foram contabilizadas áreas de instalações, centro de manejo, currais (área média de $0,8 \mathrm{~m}^{2} /$ animal) e produção de feno de capim-tifton 85 visando à alimentação do lote por um ano.

Os indicadores técnicos analisados foram: produção diária (kg PC ou kg carcaça); área utilizada (ha); número de animais terminados/ano, mão de obra total (dias-homem $/ \mathrm{mês})$, custo do feno $(R \$ / \mathrm{kg})$, custo do concentrado $(R \$ / \mathrm{kg})$, custo da ração total $(\mathrm{R} \$ / \mathrm{mês})$, fornecimento de volumoso $(\mathrm{kg} / \mathrm{mês})$ e de concentrado $(\mathrm{kg} / \mathrm{mês})$ para o lote e animais.

Os indicadores zootécnicos analisados foram:

- Produtividade (kg/animal•dia) = produção diária em kg PC ou kg carcaça/número de animais;

- Número de animais por área (animais/ha) = número de animais/área utilizada;

- Produtividade da terra (kg/ha•mês) = produção mensal em kg PC ou kg carcaça/área utilizada;

- Produtividade da mão de obra (kg PC/dia-homem) = produção diária em kg PC ou kg carcaça/total de mão de obra mensal.

O cálculo do capital investido incluiu instalações, cochos, bebedouros, autoclave, picadora, freezer e balança, de acordo com orçamento realizado na região. Foi considerada vida útil de 30 anos para o curral; 10 anos para centro de manejo, autoclave, picadora, freezer e balança; e cinco anos para cocho, saleiro e bebedouro. A depreciação foi obtida pelo método linear (HOFFMAN et al. 1987), através da seguinte fórmula: Depreciação = (valor inicial do bem - valor final do bem)/vida útil. Como valor final, $20 \%$ do valor inicial foram considerados para cochos e bebedouros e $10 \%$ para demais bens.

As despesas de custeio englobaram mão de obra familiar, alimentação, máquinas, medicamentos, energia elétrica, assistência técnica, despesas diversas e compra de animais. Além disso, naquelas foram incluídos transporte, documentação de trânsito e abate, para a comercialização da carcaça. Quanto à mão de obra, foi considerado um funcionário para manejar o lote, realizando as operações de destoxificação da torta de mamona, alimentação dos animais, limpeza das instalações e ocasionalmente, aplicação de medicamentos, sendo remunerado com salário mínimo vigente em 2010 , igual a $R \$ 510,00$, e encargos sociais $(20 \%$ do pró-labore). Para as máquinas, foram computados os gastos com a manutenção dessas, sendo igual a $13 \%$ o seu valor de compra. Os custos com medicamentos foram estimados com base no uso de vermífugos, suplemento vitamínico ADE e outros produtos. O custo com energia elétrica foi obtido por informações da Companhia Energética do Ceará (COELCE). O custo mensal com assistência técnica foi de 0,5 salário mínimo $(R \$ 255,00)$. O custo com despesas diversas é referente aos gastos com manutenção das instalações, que corresponde a $6,5 \%$ do valor das instalações. O preço de compra dos animais para terminação corresponde ao praticado na região ( $R \$ 3,20 / \mathrm{kg} P C)$.

Os custos para transporte e abate, visando à comercialização da carcaça, foi de $R \$ 120 /$ lote, $R \$ 20 / a n i m a l$ e $R \$ 1,53 /$ cabeça, respectivamente, sendo obtido por meio do valor do abate cobrado por abatedouros e do frete $(R \$ 3,00 / \mathrm{km})$ na região. Quanto ao valor da Guia de Trânsito Animal, foi obtido no sítio da Agência de Defesa Agropecuária do Estado do Ceará (ADAGRI).

O preço de venda dos produtos foi estimado a partir da análise econômica que tornasse o empreendimento (tratamento), aquele menos lucrativo, com relação benefício/custo maior ou igual a 1. De posse do preço mínimo de venda, $R \$ 4,70 / \mathrm{kg} P C$ e $R \$ 13,40 / \mathrm{kg}$ carcaça, adotado para todos os sistemas de produção, foram realizadas as análises econômicas.

Na presente pesquisa foi utilizada a mesma composição de custos observada no Sistema Integrado de Custos Agropecuários (CUSTAGRI), desenvolvido pelo Instituto de Economia Agrícola (IEA), em parceria com o Centro Nacional de Pesquisa Tecnológica em Informática para a Agricultura (EMBRAPA-CNPTIA), 
para a produção dos custos operacionais e custo total.

Os indicadores econômicos analisados foram:

- Receita bruta: $R B(R \$ / m e ̂ s$ ou $R \$ / a n o)$ = produção total em kg•preço de venda;

- Receita líquida: $R L(R \$ / a n o)=R B$ - despesas anuais (custos, depreciação e remuneração);

- Custo operacional efetivo $(\mathrm{COE})=$ despesas com manutenção de instalações e máquinas, mão de obra, assistência técnica, alimentação, medicamentos, energia, compra de animais, transporte e abate de animais;

- Custo operacional total $(\mathrm{COT})=\mathrm{COE}+$ depreciação de instalações e máquinas;

- Custo total $(C T)=$ COT + outros custos fixos (remuneração do capital investido em animais, instalações e máquinas).

Para o cálculo da remuneração do capital investido, adotou-se taxa de juros de $6 \%$ sobre o valor médio do capital empatado, referente à remuneração anual (nominal descontada a inflação) da caderneta de poupança.

- Margem bruta $(\mathrm{MB})=\mathrm{RB}-\mathrm{COE}$;

- Margem líquida $(\mathrm{ML})=\mathrm{RB}$ - COT;

- Lucro = RB - CT;

- Taxa de remuneração do capital investido (\% a.m) = ML/capital total investido;

- Capital total investido em relação à produção $(R \$ / \mathrm{kg} P C \cdot a n o$ ou $\mathrm{R} \$ / \mathrm{kg}$ carcaça・ano) = capital investido/produção anual em $\mathrm{kg}$.

Os indicadores COE, COT, CT, MB, ML e lucro foram expressos em $R \$ /$ mês, $R \$ / k g$ PC•mês ou $R \$ / k g$ carcaça•mês.

Foi utilizada como medida de eficiência a relação benefício/custo $(B / C)$, que expressa o desempenho global de todos os fatores de produção, sendo calculado pela fórmula:

$$
\mathrm{B} / \mathrm{C}=\sum \mathrm{RiO} / \Sigma(\mathrm{CiO}+\mathrm{I})
$$

onde: $\mathrm{R}=$ receita no ano 0 até $\mathrm{o}$ ano $\mathrm{i} ; \mathrm{Ci}=$ custos no ano 0 até $\mathrm{o}$ ano $\mathrm{i} ; \mathrm{I}=$ investimento.

Foi determinado o valor presente líquido (VPL), que leva em consideração o efeito do tempo sobre os valores monetários (valores reais) utilizando-se a taxa média de juros do mercado (custo de oportunidade do capital), sendo obtido por intermédio da fórmula:

$$
\mathrm{VPL}=\sum \underset{\mathrm{i}=1}{\mathrm{~B}} \underset{\mathrm{Bi}-\mathrm{Ci}) /(1+\mathrm{j}) \mathrm{i}}{\mathrm{n}}
$$

onde: $\mathrm{j}$ = taxa de desconto; $\mathrm{Bi}$ e $\mathrm{Ci}$ = fluxos de benefício e custo no período.

Foi calculada a taxa interna de retorno (TIR), que é o percentual de retorno obtido sobre o saldo investido e ainda não recuperado em um investimento, ou seja, é o percentual que expressa a rentabilidade anual média do capital alocado no projeto, durante todo o horizonte de análise do projeto, dado pela fórmula:

$$
\operatorname{TIR}=k \text {, tal que } \sum_{\mathrm{i}=1}(\mathrm{Bi}-\mathrm{Ci}) /(1+\mathrm{j}) \mathrm{i}=0
$$

onde: $\mathrm{j}$ = taxa de desconto; e $\mathrm{Bi}$ e $\mathrm{Ci}$ = fluxos de benefício e custo no período.

Para o cálculo dos indicadores foi utilizada uma taxa de juros de $6,87 \%$, baseada no valor praticado no mercado dos encargos de financiamentos a pequenos e médios produtores. Essa taxa também compatível com o rendimento médio da caderneta de poupança.

Os indicadores técnicos, zootécnicos e econômicos obtidos foram comparados por meio de análise descritiva.

\section{RESULTADOS E DISCUSSÃO}

Não houve diferença significativa entre tratamentos de destoxificação para o ganho de peso total (GPT) (Tabela 2), obtendo-se média de 10,64 kg, embora, em termos absolutos, os animais alimentados com torta autoclavada (TMACL) e tratada com fosfato monobicálcico (TMFOS) foram $24,6 \%$ e 22,5\% maiores no GPT que os alimentados com torta não tratada (NT). A eficiência alimentar (EA) dos animais alimentados com torta autoclavada foi superior aos que ingeriram torta não tratada. Os animais do sistema envolvendo torta tratada com fosfato monobicálcico obtiveram EA $11,9 \%$ maior que os animais que ingeriram NT. Com isso, animais ingerindo TMACL e TMFOS apresentaram maior produtividade, expressa em kg PC/animal•dia e kg carcaça/dia, resultando em maior número de animais terminados por ano (Tabela 3). Tratando-se da autoclavagem, esses resultados podem ser justificados pela sua eficiência na 
desnaturação da ricina (ANANDAN et al. 2005). Quanto ao fosfato monobicálcico, este produz pH ácido $(4,0)$ em solução aquosa, sendo inferior ao ponto isoelétrico ( $\mathrm{pl}$ ) da ricina de 5,2 a 5,5 (KABAT et al. 1947), o que torna carga líquida da proteína positiva e, esse excesso de cargas do mesmo sinal, pode causar repulsão eletrostática, resultando em rompimentos das ligações fracas, pontes de hidrogênio $(H)$, que mantém a estrutura terciária da proteína (LEHNINGER et al. 1995). Isso também refletiu em melhor produtividade da terra e da mão de obra dos sistemas com animais alimentados com TMACL e TMFOS. Pode ser notado que foi necessário maior fornecimento de volumoso e concentrado para esses animais, 0 que pode estar ligado ao maior consumo, em termos absolutos, pelos animais alimentados com essas rações (GOMES et al. 2012).

Tabela 2. Desempenho de ovinos alimentados com rações contendo torta de mamona submetida a métodos de destoxificação.

Table 2. Performance of sheep fed with rations containing castor cake submitted to detoxification methods.

\begin{tabular}{lllllll}
\hline \multirow{2}{*}{ Item } & \multicolumn{3}{c}{ Método de destoxificação } & & & CV (\%) \\
& NT & CC & UR & FOS & ACL & \\
\hline GPT (kg) & 9,55 & 11,0 & 9,05 & 11,7 & 11,9 & 23,09 \\
EA (g GMD/g CMS) & $0,134^{\mathrm{b}}$ & $0,147^{\mathrm{ab}}$ & $0,138^{\mathrm{b}}$ & $0,150^{\mathrm{ab}}$ & $0,160^{\mathrm{a}}$ & 10,83
\end{tabular}

GPT = ganho de peso total; EA = eficiência alimentar; NT = ração contendo torta de mamona não tratada; CC = ração contendo torta de mamona tratada com calcário calcítico; UR = ração contendo torta de mamona tratada com ureia; FOS = ração contendo torta de mamona tratada com fosfato monobicálcico; $A C L=$ ração contendo torta de mamona autoclavada. Médias seguidas de letras diferentes indicam que houve diferença pelo teste de Tukey $(p<0,05)$.

Tabela 3. Indicadores técnicos e zootécnicos da produção de ovinos alimentados com rações contendo torta de mamona submetida a métodos de destoxificação.

Table 3. Technical and animal production indicators of production of sheep fed with rations containing castor cake submitted to detoxification methods.

\begin{tabular}{llllll}
\hline \multirow{2}{*}{ Item } & \multicolumn{5}{c}{ Método de destoxificação } \\
& NT & CC & UR & FOS & ACL \\
\hline \multicolumn{1}{c}{ Indicadores técnicos } & & & & & \\
Produção diária (kg PC) & 29,2 & 33,2 & 28,7 & 37,2 & 39,0 \\
Produção diária (kg carcaça) & 13,7 & 15,4 & 13,4 & 17,6 & 18,3 \\
Área utilizada (ha) & 1,07 & 1,11 & 1,03 & 1,20 & 1,21 \\
Número de animais/lote & 250 & 250 & 250 & 250 & 250 \\
Número de animais terminados/ano & 833 & 939 & 820 & 1042 & 1087 \\
Mão de obra total (dias-homem/mês) & 7,50 & 7,50 & 7,50 & 7,50 & 7,50 \\
Custo do feno (R\$/kg) & 0,42 & 0,42 & 0,42 & 0,42 & 0,42 \\
Custo do concentrado (R\$/kg) & 0,681 & 0,685 & 0,683 & 0,695 & 0,686 \\
Custo da ração total (R\$/kg) & 0,550 & 0,553 & 0,551 & 0,558 & 0,553 \\
Volumoso para o lote (kg/mês) & 4.151 & 4.254 & 4.010 & 4.587 & 4.603 \\
Concentrado para o lote (kg/mês) & 3.512 & 3.627 & 3.422 & 3.901 & 3.798 \\
$\quad$ Indicadores zootécnicos & & & & & \\
PROD animal (kg PC/animal•dia) & 0,117 & 0,133 & 0,115 & 0,149 & 0,156 \\
№ animais/ha para produção de PC & 233 & 226 & 242 & 208 & 207 \\
PROD da terra (kg PC/ha•mês) & 848 & 933 & 864 & 960 & 998 \\
PROD da MO (kg PC/dia-homem) & 3,90 & 4,43 & 3,83 & 4,97 & 5,20 \\
PROD animal (kg CAR/dia) & 0,05 & 0,06 & 0,05 & 0,07 & 0,07 \\
№ animais/ha para produção de CAR & 233 & 226 & 242 & 208 & 207 \\
PROD da terra (kg CAR/ha•mês) & 398 & 433 & 404 & 454 & 469 \\
PROD da MO (kg CAR/dia-homem) & 1,83 & 2,06 & 1,79 & 2,35 & 2,44 \\
\end{tabular}

$\overline{\mathrm{PC}}$ = peso corporal; CAR = carcaça; $\mathrm{PROD}=$ produtividade; $\mathrm{MO}=$ mão de obra; $\mathrm{NT}$ = ração contendo torta de mamona não tratada; $\mathrm{CC}=$ ração contendo torta de mamona tratada com calcário calcítico; UR = ração contendo torta de mamona tratada com ureia; FOS = ração contendo torta de mamona tratada com fosfato monobicálcico; $\mathrm{ACL}=$ ração contendo torta de mamona autoclavada. 
No que diz respeito à área utilizada para a atividade, grande parte foi para a produção do feno de capim tifton 85 , tendo em vista que a ração foi composta por $50 \%$ de volumoso. Os sistemas que exigiram maiores áreas total no confinamento são aqueles com maiores exigências de área para a capineira, que foram os sistemas com TMACL e TMFOS.

O número de animais por hectare, um indicador de intensificação do sistema de produção (VIEIRA 2009), apresentou variação de 207 a 242 animais/ha, ocorrendo menores valores para os sistemas de produção que apresentaram a necessidade de maiores áreas para produção de feno, considerando que todos os sistemas foram simulados com 250 animais por lote. Tendo em vista que um sistema de confinamento envolve mais custos em comparação a sistemas extensivos, é necessário naquele trabalhar com uma taxa de lotação maior que o utilizado em pastagens, para que compense os maiores investimentos. Tais valores de número de animais/ha podem ser comparados aos obtidos por POMPEU (2009), que obteve variação de 218 a 270 animais/ha, quando este trabalhou com ovinos em confinamento na substituição de farelo de soja pela torta de mamona autoclavada (0, 33, 67 e 100\%), levando em consideração que o presente trabalho testou, além da autoclavagem, outros métodos de destoxificação, bem como focou em apenas um nível de substituição pela torta de mamona (67\%). Quanto ao número de animais do lote, ANDRADE et al. (2011), estudando a viabilidade econômica de ovinos em confinamento alimentados com feno de capim-elefante como volumoso e farelo de soja como fonte proteica na ração concentrada, verificaram que o ideal para tornar viável o sistema é a utilização de no mínimo 200 animais, com preço de venda de $R \$ 3,27 / \mathrm{kg} P C$, quando comparado com a simulação para 100 animais $(R \$ 3,75 / \mathrm{kg}$ PC), sendo menor que o estudado no presente trabalho (250 animais por lote), dado que no presente foi adotado um período de vazio sanitário, o que necessitou aumentar o tamanho do lote para proporcionar maior diluição dos custos.

Tabela 4. Custos de implantação da produção de peso corporal e carcaça em ovinos alimentados com rações contendo torta de mamona submetida a métodos de destoxificação.

Table 4. Establishment costs of body weight production and carcass production in sheep fed with rations containing castor cake submitted to detoxification methods.

\begin{tabular}{|c|c|c|c|c|c|c|c|c|c|c|}
\hline \multirow{3}{*}{ Item } & \multicolumn{10}{|c|}{ Método de Destoxificação } \\
\hline & \multicolumn{2}{|c|}{ NT } & \multicolumn{2}{|c|}{$\mathrm{CC}$} & \multicolumn{2}{|c|}{ UR } & \multicolumn{2}{|c|}{ FOS } & \multicolumn{2}{|c|}{$\mathrm{ACL}$} \\
\hline & PrT & PrFin & PrT & PrFin & $\operatorname{PrT}$ & PrFin & PrT & PrFin & PrT & PrFin \\
\hline & \multicolumn{10}{|c|}{ Despesas com investimentos (Peso corporal) } \\
\hline CE & 10 & 0,013 & 10 & 0,012 & 10 & 0,014 & 10 & 0,011 & 10 & 0,010 \\
\hline $\mathrm{CM}$ & 4 & 0,016 & 4 & 0,014 & 4 & 0,016 & 4 & 0,013 & 4 & 0,012 \\
\hline Cocho & 0,75 & 0,006 & 0,75 & 0,005 & 0,75 & 0,006 & 0,75 & 0,005 & 0,75 & 0,005 \\
\hline BEB & 0,32 & 0,003 & 0,32 & 0,002 & 0,32 & 0,003 & 0,32 & 0,002 & 0,32 & 0,002 \\
\hline AUTO & 0 & 0 & 0 & 0 & 0 & 0 & 0 & 0 & 48 & 0,147 \\
\hline Picadora & 3 & 0,012 & 3 & 0,011 & 3 & 0,012 & 3 & 0,010 & 3 & 0,009 \\
\hline Balança & 2,93 & 0,012 & 2,93 & 0,010 & 2,93 & 0,012 & 2,93 & 0,009 & 2,93 & 0,009 \\
\hline Outros $^{1}$ & 1,05 & 0,003 & 1,050 & 0,003 & 1,050 & 0,003 & 1,050 & 0,002 & 3,45 & 0,010 \\
\hline \multirow[t]{2}{*}{ Total } & 22,0 & 0,065 & 22,0 & 0,057 & 22,0 & 0,066 & 22,0 & 0,052 & 72,4 & 0,204 \\
\hline & \multicolumn{10}{|c|}{ Despesas com investimentos (Carcaça) } \\
\hline CE & 10 & 0,031 & 10 & 0,027 & 10 & 0,033 & 10 & 0,023 & 10 & 0,022 \\
\hline $\mathrm{CM}$ & 4 & 0,038 & 4 & 0,032 & 4 & 0,040 & 4 & 0,027 & 4 & 0,027 \\
\hline Cocho & 0,75 & 0,014 & 0,75 & 0,012 & 0,75 & 0,015 & 0,75 & 0,010 & 0,75 & 0,010 \\
\hline BEB & 0,32 & 0,006 & 0,32 & 0,005 & 0,32 & 0,006 & 0,32 & 0,004 & 0,32 & 0,004 \\
\hline AUTO & 0 & 0 & 0 & 0 & 0 & 0 & 0 & 0 & 48 & 0,321 \\
\hline Picadora & 3 & 0,028 & 3 & 0,024 & 3 & 0,030 & 3 & 0,021 & 3 & 0,020 \\
\hline Freezer & 1,85 & 0,017 & 1,85 & 0,015 & 1,85 & 0,019 & 1,85 & 0,013 & 1,85 & 0,012 \\
\hline Balança & 2,93 & 0,028 & 2,93 & 0,024 & 2,93 & 0,029 & 2,93 & 0,020 & 2,93 & 0,020 \\
\hline Outros $^{1}$ & 1,14 & 0,008 & 1,14 & 0,007 & 1,14 & 0,009 & 1,14 & 0,006 & 3,54 & 0,022 \\
\hline Total & 24 & 0,170 & 24 & 0,146 & 24 & 0,181 & 24 & 0,124 & 74,4 & 0,458 \\
\hline
\end{tabular}

$15 \%$ das despesas com investimento; $\mathrm{CE}=$ curral de engorda; $\mathrm{CM}=$ centro de manejo; BEB = bebedouro; $\mathrm{AUTO}=$ autoclave; PrT = preço total $(\mathrm{R} \$ / 1.000) ; \mathrm{PrFin}=$ preço final $(\mathrm{R} \$ / \mathrm{kg} \mathrm{PC}) ; \mathrm{NT}=$ ração contendo torta de mamona não tratada; $\mathrm{CC}=$ ração contendo torta de mamona tratada com calcário calcítico; UR = ração contendo torta de mamona tratada com ureia; FOS = ração contendo torta de mamona tratada com fosfato monobicálcico; $\mathrm{ACL}$ = ração contendo torta de mamona autoclavada. 
No tocante à produtividade animal, produtividade da terra e mão de obra, calculadas para produção de carcaça, foram observados menores valores em comparação aos da produção de peso corporal (PC), os quais têm relação com o menor peso das carcaças em relação ao $\mathrm{PC}$, devido às perdas decorrentes do abate dos animais.

Quanto aos custos de implantação, o item que apresentou maior participação, considerando sistema de produção com TMACL, foi a aquisição da autoclave (Tabela 4), explicando os altos custos de implantação desse sistema. Foi observado que o sistema de produção com animais alimentados com TMFOS apresentou menor valor total, expresso em $R \$ / k g P C$, de despesas com investimento, estando relacionado à boa produtividade desses animais, que proporcionou maior diluição dos custos. Nas despesas com investimentos para comercialização das carcaças, pôde ser observado que a necessidade de freezers para conservação da carcaça resultou em custo de implantação total maior para todos os tratamentos em comparação com despesas para comercialização do PC.

Analisando os custos de manutenção anual (total), os sistemas com animais alimentados com TMACL e TMFOS apresentaram maiores valores (Tabela 5) devido ao melhor desempenho dos animais desses tratamentos, o que resultou, segundo POMPEU (2009), na maior rotatividade do sistema e, consequentemente, na maior compra de animais para terminação. Por terem apresentado maiores produtividades, esses tratamentos tornaram-se mais vantajosos, considerando as despesas de custeio em relação ao PC produzido.

Tabela 5. Custos de manutenção anual da produção de peso corporal e carcaça em ovinos alimentados com rações contendo torta de mamona submetida a métodos de destoxificação.

Table 5. Annual maintenance costs of body weight production and carcass production in sheep fed with rations containing castor cake submitted to detoxification methods.

Método de Destoxificação

\begin{tabular}{|c|c|c|c|c|c|c|c|c|c|c|}
\hline \multirow[t]{2}{*}{ Item } & \multicolumn{2}{|c|}{ NT } & \multicolumn{2}{|c|}{$\mathrm{CC}$} & \multicolumn{2}{|c|}{ UR } & \multicolumn{2}{|c|}{ FOS } & \multicolumn{2}{|c|}{ ACL } \\
\hline & PrTot & PrFin & PrTot & PrFin & PrTot & PrFin & PrTot & PrFin & PrTot & PrFin \\
\hline & \multicolumn{10}{|c|}{ Despesas de custeio (Peso corporal) } \\
\hline MO & 7,344 & 0,29 & 7,344 & 0,26 & 7,344 & 0,30 & 7,344 & 0,23 & 7,344 & 0,23 \\
\hline ALI & 49,603 & 1,99 & 51,745 & 1,84 & 48,203 & 1,96 & 56,680 & 1,81 & 55,563 & 1,70 \\
\hline MAQ & 1,012 & 0,04 & 1,012 & 0,04 & 1,012 & 0,04 & 1,012 & 0,03 & 1,012 & 0,03 \\
\hline MED & 1,208 & 0,05 & 1,361 & 0,05 & 1,188 & 0,05 & 1,511 & 0,05 & 1,577 & 0,05 \\
\hline $\mathrm{EE}$ & 0,520 & 0,02 & 0,520 & 0,02 & 0,520 & 0,02 & 0,520 & 0,02 & 0,520 & 0,02 \\
\hline AT & 3,060 & 0,12 & 3,060 & 0,11 & 3,060 & 0,12 & 3,060 & 0,10 & 3,060 & 0,09 \\
\hline DD & 0,959 & 0,04 & 0,959 & 0,03 & 0,959 & 0,04 & 0,959 & 0,03 & 0,959 & 0,03 \\
\hline CA & 47,972 & 1,92 & 54,060 & 1,92 & 47,203 & 1,92 & 60,043 & 1,92 & 62,629 & 1,92 \\
\hline \multirow[t]{2}{*}{$\mathrm{T}$} & 111,68 & 4,47 & 120,06 & 4,27 & 109,49 & 4,45 & 131,13 & 4,19 & 132,66 & 4,07 \\
\hline & \multicolumn{10}{|c|}{ Despesas de custeio (Carcaça) } \\
\hline MO & 7,344 & 0,69 & 7,344 & 0,59 & 7,344 & 0,74 & 7,344 & 0,50 & 7,344 & 0,49 \\
\hline ALI & 49,603 & 4,66 & 51,745 & 4,16 & 48,203 & 4,85 & 56,680 & 3,88 & 55,563 & 3,72 \\
\hline MA & 1,012 & 0,10 & 1,012 & 0,08 & 1,012 & 0,10 & 1,012 & 0,07 & 1,012 & 0,07 \\
\hline MED & 1,208 & 0,11 & 1,361 & 0,11 & 1,188 & 0,12 & 1,511 & 0,10 & 1,577 & 0,11 \\
\hline $\mathrm{EE}$ & 0,520 & 0,05 & 0,520 & 0,04 & 0,520 & 0,05 & 0,520 & 0,04 & 0,520 & 0,03 \\
\hline AT & 3,060 & 0,29 & 3,060 & 0,25 & 3,060 & 0,31 & 3,060 & 0,21 & 3,060 & 0,20 \\
\hline DD & 0,959 & 0,09 & 0,959 & 0,08 & 0,959 & 0,10 & 0,959 & 0,07 & 0,959 & 0,06 \\
\hline CA & 47,972 & 4,51 & 54,060 & 4,35 & 47,203 & 4,74 & 60,043 & 4,11 & 62,629 & 4,20 \\
\hline TA & 18,431 & 1,73 & 20,770 & 1,67 & 18,136 & 1,82 & 23,069 & 1,58 & 24,062 & 1,61 \\
\hline $\mathrm{T}$ & 130,111 & 12,23 & 140,833 & 11,33 & 127,622 & 12,83 & 154,200 & 10,56 & 156,733 & 10,49 \\
\hline
\end{tabular}

${ }^{1} \mathrm{MO}$ = mão de obra; $\mathrm{ALI}$ = alimentação; $\mathrm{MAQ}$ = máquinas; $\mathrm{MED}$ = medicamentos; $\mathrm{EE}$ = energia elétrica; $\mathrm{AT}$ = assistência técnica; $\mathrm{DD}=$ despesas diversas; $\mathrm{CA}=$ Compra de animais; $\mathrm{TA}=$ Transporte e abate dos animais; $\mathrm{T}=$ total; $\operatorname{PrTot}=$ preço total $(\mathrm{R} \$ / 1.000 / \mathrm{ano}) ; \mathrm{PrFin}$ $=$ preço final $(\mathrm{R} \$ / \mathrm{kg} \mathrm{PC}) ; \mathrm{NT}$ = ração contendo torta de mamona não tratada; $\mathrm{CC}$ = ração contendo torta de mamona tratada com calcário calcítico; UR = ração contendo torta de mamona tratada com ureia; FOS = ração contendo torta de mamona tratada com fosfato monobicálcico; $A C L=$ ração contendo torta de mamona autoclavada. 
de abate terminado por ano, não apresentou variação entre tratamentos, sendo de $R \$ 1,92 / \mathrm{Kg} P C$. Isso ocorreu porque à medida que a produção de PC se elevou, a compra de animais aumentou proporcionalmente, tornando esse valor constante. Entretanto, quando o custo com compra de animais foi relacionado ao peso de carcaça, notou-se que houve uma variação entre tratamentos, sendo explicado pelo fato de a compra de animais ter sido feita de acordo com o número de lotes terminados por ano, que por sua vez foi estimado com base no ganho médio diário. Então, quando compra de animais foi dividida pelo peso de carcaça, notou-se que o peso e o rendimento de carcaça podem ter contribuído para essa variação. Esses custos foram menores nos sistemas de produção com TMFOS e TMACL, devido à maior produção de PC dos animais alimentados com essas rações e, assim, obtenção de carcaças mais pesadas, diluindo os custos com compra de animais.

Foi constatado que os itens com maior representatividade, nas despesas de custeio, foram compra de animais e alimentação (Tabela 6). Os sistemas de produção em que os animais foram alimentados com torta autoclavada ou tratada com fosfato monobicálcico obtiveram melhores resultados, já que, apesar das despesas com alimentação terem sido maiores que nos demais tratamentos, a maior produção de PC proporcionou diluição desses custos. Esses resultados corroboram com BARROS et al. (2005) e BESERRA (2010), os quais verificaram que os principais custos são com compra de animais e alimentação, para sistema de produção de ovinos mestiços $1 / 2$ Dorper x $1 / 2$ Santa Inês alimentados com capim elefante ad libitum e concentrado (1,5;2,5 e 3,5\% do peso corporal) e níveis de substituição ( $0 ; 33 ; 67$ e $100 \%)$ do feno de capim tifton 85 pela casca de mamona, respectivamente.

Tabela 6. Custos de manutenção anual em \% da produção de peso corporal e carcaça em ovinos alimentados com rações contendo torta de mamona submetida a métodos de destoxificação.

Table 6. Annual maintenance costs in \% of body weight production and carcass production in sheep fed with rations containing castor cake submitted to detoxification methods.

\begin{tabular}{|c|c|c|c|c|c|}
\hline \multirow[b]{2}{*}{ Item } & \multicolumn{5}{|c|}{ Método de Destoxificação } \\
\hline & $\begin{array}{c}\text { NT } \\
\% / A n o\end{array}$ & $\begin{array}{c}\text { CC } \\
\% / \text { Ano }\end{array}$ & $\begin{array}{l}\text { UR } \\
\% / A n o\end{array}$ & $\begin{array}{c}\text { FOS } \\
\% / A n o\end{array}$ & $\begin{array}{c}\text { ACL } \\
\% / A n o\end{array}$ \\
\hline & \multicolumn{5}{|c|}{ Despesas de custeio (Peso corporal) } \\
\hline MO familiar & 6,58 & 6,12 & 6,71 & 5,60 & 5,54 \\
\hline Alimentação & 44,42 & 43,10 & 44,03 & 43,22 & 41,88 \\
\hline Máquinas & 0,91 & 0,84 & 0,92 & 0,77 & 0,76 \\
\hline Medicamentos & 1,08 & 1,13 & 1,09 & 1,15 & 1,19 \\
\hline Energia elétrica & 0,47 & 0,43 & 0,48 & 0,40 & 0,39 \\
\hline Assistência técnica & 2,74 & 2,55 & 2,79 & 2,33 & 2,31 \\
\hline Despesas diversas & 0,86 & 0,80 & 0,88 & 0,73 & 0,72 \\
\hline Compra de animais & 42,96 & 45,03 & 43,11 & 45,79 & 47,21 \\
\hline \multirow[t]{2}{*}{ Total } & 100 & 100 & 100 & 100 & 100 \\
\hline & \multicolumn{5}{|c|}{ Despesas de custeio (Carcaça) } \\
\hline MO familiar & 5,64 & 5,21 & 5,75 & 4,76 & 4,69 \\
\hline Alimentação & 38,12 & 36,74 & 37,77 & 36,76 & 35,45 \\
\hline Máquinas & 0,78 & 0,72 & 0,79 & 0,66 & 0,65 \\
\hline Medicamentos & 0,93 & 0,97 & 0,93 & 0,98 & 1,01 \\
\hline Energia elétrica & 0,40 & 0,37 & 0,41 & 0,34 & 0,33 \\
\hline Assistência técnica & 2,35 & 2,17 & 2,40 & 1,98 & 1,95 \\
\hline Despesas diversas & 0,74 & 0,68 & 0,75 & 0,62 & 0,61 \\
\hline Compra de animais & 36,87 & 38,39 & 36,99 & 38,94 & 39,96 \\
\hline Transporte e abate ${ }^{1}$ & 14,17 & 14,75 & 14,21 & 14,86 & 15,35 \\
\hline Total & 100 & 100 & 100 & 100 & 100 \\
\hline
\end{tabular}

${ }^{1}$ Custos com transporte e abate dos animais; $\mathrm{MO}$ = mão de obra; NT = ração contendo torta de mamona não tratada; CC = ração contendo torta de mamona tratada com calcário calcítico; UR = ração contendo torta de mamona tratada com ureia; FOS = ração contendo torta de mamona tratada com fosfato monobicálcico; $\mathrm{ACL}$ = ração contendo torta de mamona autoclavada.

A receita bruta foi superior para os sistemas de produção nos quais os animais foram alimentados com TMACL e TMFOS (Tabela 7 e Tabela 8). A menor receita bruta foi para o sistema envolvendo animais alimentados com torta tratada com ureia (TMUR), considerando seus baixos valores de ganho de peso total 
e eficiência alimentar. Comparando receita obtida da venda de carcaça com de PC, ocorreu maior receita na venda da carne, visto que seu preço de comercialização é maior que o do PC. COSTA et al. (2008), caracterizando sistemas de produção de caprinos e ovinos do semiárido da Paraíba, verificaram que a renda bruta anual dos produtores de ovinos variou de $R \$ 369,00$ a $R \$ 5.979,00$, bem inferior à do presente estudo, podendo ser justificado por aqueles sistemas serem predominantemente extensivos, com pouco uso de técnicas de manejo, sendo a pastagem nativa utilizada na alimentação do rebanho por 92 a $100 \%$ desses produtores.

Tabela 7. Indicadores econômico-financeiros da produção de peso corporal em ovinos alimentados com rações contendo torta de mamona submetida a métodos de destoxificação.

Table 7. Economic and financial indicators of the body weight production in sheep fed with rations containing castor cake submitted to detoxification methods.

\begin{tabular}{|c|c|c|c|c|c|}
\hline \multirow{2}{*}{ Item } & \multicolumn{5}{|c|}{ Método de destoxificação } \\
\hline & NT & $\mathrm{CC}$ & UR & FOS & $\mathrm{ACL}$ \\
\hline Receita bruta (R\$/mês) & $9.785,94$ & $11.027,84$ & $9.629,17$ & $12.248,40$ & $12.775,84$ \\
\hline Preço do PC (R\$/kg) & 4,70 & 4,70 & 4,70 & 4,70 & 4,70 \\
\hline COE (R\$/mês) & $9.306,49$ & $10.005,10$ & $9.124,21$ & $10.927,55$ & $11.055,33$ \\
\hline COT (R\$/mês) & $9.430,02$ & $10.128,63$ & $9.247,74$ & $11.051,08$ & $11.556,86$ \\
\hline Custo total (R\$/mês) & $9.638,75$ & $10.337,36$ & $9.456,46$ & $11.259,80$ & $12.054,13$ \\
\hline Margem bruta (R\$/mês) & 479,45 & $1.022,73$ & 504,97 & $1.320,86$ & $1.720,51$ \\
\hline ML (R\$/mês) & 355,91 & 899,20 & 381,43 & $1.197,32$ & $1.218,97$ \\
\hline Lucro (R\$/mês) & 147,19 & 690,48 & 172,71 & 988,60 & 721,71 \\
\hline $\mathrm{COE}(\mathrm{R} \$ / \mathrm{kg} \mathrm{PC})$ & 4,47 & 4,26 & 4,45 & 4,19 & 4,07 \\
\hline COT $(\mathrm{R} \$ / \mathrm{kg} \mathrm{PC})$ & 4,53 & 4,32 & 4,51 & 4,24 & 4,25 \\
\hline Custo total (R\$/kg PC) & 4,63 & 4,41 & 4,62 & 4,32 & 4,43 \\
\hline Margem bruta $(\mathrm{R} \$ / \mathrm{kg} \mathrm{PC})$ & 0,23 & 0,44 & 0,25 & 0,51 & 0,63 \\
\hline $\mathrm{ML}(\mathrm{R} \$ / \mathrm{kg} \mathrm{PC})$ & 0,17 & 0,38 & 0,19 & 0,46 & 0,45 \\
\hline Lucro (R\$/kg PC) & 0,07 & 0,29 & 0,08 & 0,38 & 0,27 \\
\hline TR do Cl (\% a.m.) & 1,61 & 4,08 & 1,73 & 5,43 & 1,68 \\
\hline $\mathrm{Cl}(\mathrm{R} \$ / k g$ PC•ano) & 0,88 & 0,78 & 0,90 & 0,71 & 2,22 \\
\hline Investimento $(\mathrm{R} \$)$ & $22.058,40$ & $22.058,40$ & $22.058,40$ & $22.058,40$ & $72.458,40$ \\
\hline Custo (R\$/ano) & $115.664,9$ & $124.048,3$ & $113.477,6$ & $135.117,6$ & $144.649,5$ \\
\hline Receita bruta (R\$/ano) & $117.431,2$ & $132.334,0$ & $115.550,1$ & $146.980,8$ & $153.310,0$ \\
\hline Receita líquida (R\$/ano) & $1.766,28$ & $8.285,73$ & $2.072,51$ & $11.863,21$ & $8.660,51$ \\
\hline Relação Benefício/Custo & 1,00 & 1,05 & 1,00 & 1,07 & 1,02 \\
\hline VPL $(\mathrm{R} \$)$ & $1.772,62$ & $47.838,98$ & $3.936,45$ & $73.117,34$ & $26.021,32$ \\
\hline TIR (\%) & 8 & 38 & 9 & 54 & 12 \\
\hline
\end{tabular}

$\mathrm{PC}=$ peso corporal; $\mathrm{COE}=$ custo operacional efetivo; $\mathrm{COT}=$ custo operacional total; $\mathrm{ML}=$ margem líquida; $\mathrm{TR}=$ taxa de remuneração; $\mathrm{Cl}$ = capital investido; VPL = valor presente líquido; TIR = taxa interna de retorno; NT = ração contendo torta de mamona não tratada; $\mathrm{CC}=$ ração contendo torta de mamona tratada com calcário calcítico; UR = ração contendo torta de mamona tratada com ureia; FOS = ração contendo torta de mamona tratada com fosfato monobicálcico; $\mathrm{ACL}$ = ração contendo torta de mamona autoclavada.

Custo operacional efetivo (COE), custo operacional total (COT) e custo total (CT) mensais foram maiores no sistema com destoxificação da torta por autoclavagem e pelo fosfato monobicálcico. Aquele sistema exige maior capital investido e custos adicionais com energia elétrica para processamento e este, necessidade de agente químico de maior preço de aquisição. Além disso, em ambos foi constatado que o fornecimento de concentrado e volumoso para esses animais e o número de animais comprados anualmente para terminação influenciaram no aumento dessas variáveis.

Os sistemas de produção que apresentaram menores COE, COT e CT foram com utilização da torta tratada com ureia e torta não tratada, resultante do menor fornecimento de volumoso e concentrado e menor número de animais comprados anualmente. Com relação aos custos para produção de carcaças, foram observados que esses tratamentos também foram os que tiveram menores custos. Por outro lado, os tratamentos que tiveram maiores custos ( $\mathrm{R} \$ / \mathrm{ano})$ para produção de $\mathrm{PC}$ apresentaram maiores custos para produção de carcaças. É importante ressaltar que esta exige novos custos em relação à produção de PC, com transporte dos animais até o abatedouro, encargos com documentação de transporte dos animais (Guia de Trânsito Animal (GTA)), despesas para a realização do abate, depreciação e remuneração dos 
freezers utilizados para conservação da carne.

Tabela 8. Indicadores econômico-financeiros da produção de carcaça em ovinos alimentados com rações contendo torta de mamona submetida a métodos de destoxificação.

Table 8. Economic and financial indicators of the carcass production in sheep fed with rations containing castor cake submitted to detoxification methods.

\begin{tabular}{|c|c|c|c|c|c|}
\hline \multirow{2}{*}{ Item } & \multicolumn{5}{|c|}{ Método de destoxificação } \\
\hline & NT & $\mathrm{CC}$ & UR & FOS & $\mathrm{ACL}$ \\
\hline$\overline{\mathrm{RB}}(\mathrm{R} \$ /$ mês $)$ & $11.876,24$ & $13.886,47$ & $11.109,47$ & $16.296,46$ & $16.670,38$ \\
\hline Preço ( $R \$ / k g$ CAR) & 13,40 & 13,40 & 13,40 & 13,40 & 13,40 \\
\hline COE (R\$/mês) & $10.842,40$ & $11.735,92$ & $10.635,51$ & $12.849,94$ & $13.060,50$ \\
\hline COT (R\$/mês) & $10.980,50$ & $11.874,02$ & $10.773,61$ & $12.988,04$ & $13.576,60$ \\
\hline $\mathrm{CT}$ (R\$/mês) & $11.200,34$ & $12.093,87$ & $10.993,46$ & $13.207,88$ & $14.084,99$ \\
\hline MB (R\$/mês) & $1.033,84$ & $2.150,54$ & 473,96 & $3.446,52$ & $3.609,88$ \\
\hline ML (R\$/mês) & 895,74 & $2.012,44$ & 335,86 & $3.308,42$ & $3.093,78$ \\
\hline Lucro (R\$/mês) & 675,90 & $1.792,60$ & 116,02 & $3.088,57$ & $2.585,39$ \\
\hline $\operatorname{COE}(\mathrm{R} \$ / \mathrm{kg} \mathrm{CAR})$ & 12,23 & 11,32 & 12,83 & 10,57 & 10,50 \\
\hline COT (R\$/kg CAR) & 12,39 & 11,46 & 12,99 & 10,68 & 10,91 \\
\hline CT (R\$/kg CAR) & 12,64 & 11,67 & 13,26 & 10,86 & 11,32 \\
\hline $\mathrm{MB}(\mathrm{R} \$ / \mathrm{kg} \mathrm{CAR})$ & 1,17 & 2,08 & 0,57 & 2,83 & 2,90 \\
\hline $\mathrm{ML}(\mathrm{R} \$ / \mathrm{kg} \mathrm{CAR})$ & 1,01 & 1,94 & 0,41 & 2,72 & 2,49 \\
\hline Lucro (R\$/kg CAR) & 0,76 & 1,73 & 0,14 & 2,54 & 2,08 \\
\hline TR do Cl (\% a.m.) & 3,73 & 8,38 & 1,40 & 13,78 & 4,16 \\
\hline $\mathrm{Cl}$ & 2,26 & 1,93 & 2,41 & 1,64 & 4,98 \\
\hline Investimento ( $R \$)$ & $24.000,90$ & $24.000,90$ & $24.000,90$ & $24.000,90$ & $74.400,90$ \\
\hline Custo (R\$/ano) & $134.404,1$ & $145.126,4$ & $131.921,5$ & $158.494,6$ & $169.019,9$ \\
\hline RB (R\$/ano) & $142.514,9$ & $166.637,6$ & $133.313,6$ & $195.557,5$ & $200.044,6$ \\
\hline $\mathrm{RL}(\mathrm{R} \$ / \mathrm{ano})$ & $8.110,78$ & $21.511,19$ & $1.392,18$ & $37.062,89$ & $31.024,72$ \\
\hline Relação B/C & 1,05 & 1,13 & 1,00 & 1,22 & 1,14 \\
\hline VPL (R\$) & $45.659,8$ & $140.346,9$ & $-1.813,7$ & $250.234,9$ & $183.103,5$ \\
\hline TIR (\%) & 34 & 90 & 6 & 154 & 42 \\
\hline
\end{tabular}

CAR = carcaça; RB = receita bruta; $\mathrm{COE}$ = custo operacional efetivo; COT = custo operacional total; CT = custo total; $\mathrm{MB}=\mathrm{margem}$ bruta; $\mathrm{ML}=$ margem líquida; $\mathrm{TR}=$ taxa de remuneração; $\mathrm{Cl}=$ capital investido $(\mathrm{R} \$ / \mathrm{kg} \mathrm{CAR} \cdot \mathrm{ano}) ; \mathrm{RL}=$ receita líquida; $\mathrm{B} / \mathrm{C}=$ benefício/custo; VPL = valor presente líquido; TIR = taxa interna de retorno; NT = ração contendo torta de mamona não tratada; $C \mathrm{C}=$ ração contendo torta de mamona tratada com calcário calcítico; UR = ração contendo torta de mamona tratada com ureia; FOS = ração contendo torta de mamona tratada com fosfato monobicálcico; $\mathrm{ACL}$ = ração contendo torta de mamona autoclavada.

AMARAL et al. (2011), ao avaliar cordeiros Santa Inês, $1 / 2$ White Dorper-Santa Inês e $1 / 2$ Dorper-Santa Inês confinados, obtiveram custo de produção de $\mathrm{R} \$ 8,25, \mathrm{R} \$ 8,28$ e $\mathrm{R} \$ 8,55 / \mathrm{kg}$ carcaça, valores inferiores aos obtidos neste estudo, o que pode ser explicado pela melhor conversão alimentar daqueles $(4,14 ; 3,52 \mathrm{e}$ $3,65)$ em contraposição à menor EA dos animais do presente trabalho. PAIM et al. (2011), ao estudar cordeiros cruzados confinados abatidos em diferentes pesos, obtiveram custo operacional de $\mathrm{R} \$ 3,74 / \mathrm{kg} P C$ e 7,31/kg carcaça, sendo inferior ao presente estudo, dado que aquele trabalho considerou custo operacional apenas alimentação, mão de obra e custos sanitários, enquanto o presente estudo, além disso, incluiu gastos com manutenção das máquinas e instalações, energia elétrica, assistência técnica, compra de animais, abate e depreciação.

Todos os sistemas proporcionaram lucro, considerando o preço de venda adotado para PC e carcaça. O maior lucro foi observado no sistema em que os animais foram alimentados com torta tratada com fosfato monobicálcico, onde, mesmo havendo acréscimo de custo para destoxificação, a resposta biológica dos animais compensou esses gastos, propiciando maior eficiência de produção, enquanto, no sistema de produção controle, utilizando torta de mamona não tratada, o custo total teve acréscimo de $R \$ 0,31$ por quilograma de $\mathrm{PC}$ e teve decréscimo de $\mathrm{R} \$ 841,41$ no lucro mensal em relação àquele sistema. O lucro do sistema com TMFOS deste estudo foi melhor em comparação com o lucro obtido por sistemas utilizando torta de mamona autoclavada por outros autores, como POMPEU (2009), que obteve lucro de $R \$ 0,35 / \mathrm{kg}$ PC, para o nível de $67 \%$ de substituição do farelo de soja pela torta de mamona autoclavada, e VIEIRA 
(2009), que não obteve lucro para nenhum dos sistemas envolvendo ovinos alimentados com farelo de mamona autoclavado. Os indicadores relação benefício/custo $(B / C)$, valor presente líquido $(V P L)$ e taxa interna de retorno (TIR), na produção de PC e de carcaça, também indicam como melhor investimento o sistema com TMFOS.

Os valores de B/C, VPL e TIR foram maiores para produção de carcaça quando comparados com produção de PC, na maioria dos sistemas de produção, mostrando que a melhor opção para o produtor pode ser a venda da carcaça dos seus animais. Tendo em vista que a relação benefício/custo superior a um indica que as receitas superam os investimentos, os sistemas que se mostraram favoráveis, na produção de PC, foram utilizando torta tratada com calcário calcítico (TMCC), TMFOS e TMACL, sendo melhor quando a torta foi tratada com fosfato monobicálcico, no qual para cada $R \$ 1,00$ aplicado no sistema de produção, resultaria em $R \$ 1,07$ (produção de PC) em receita, tornando o projeto factível. No que tange ao VPL, pôdese verificar que todos os tratamentos apresentaram valor positivo na produção de $\mathrm{PC}$, indicando que o valor presente das entradas de caixa é, no mínimo, igual ao valor presente das saídas de caixa, caracterizando o investimento como viável. No que se referem à taxa interna de retorno (TIR), também na produção de PC, todos os sistemas de produção apresentaram TIR superior à taxa de juros de $6,87 \%$ a.a.

O sistema que obteve maior lucro na venda do PC também foi o que mostrou melhor resultado com a venda da carcaça. A cada $R \$ 1,00$ aplicado na produção de carcaça, há acréscimo de $R \$ 1,22$ na receita do sistema de produção utilizando o fosfato monobicálcico para tratamento da torta de mamona. Para a torta de mamona não tratada, retornará na forma de receita $R \$ 1,05$. Na produção de carcaças, o sistema com TMUR apresentou VPL negativo, demonstrando a inviabilidade desse sistema, bem como TIR inferior à taxa de juros. O VPL dos demais tratamentos foi superior a zero, sendo os projetos factíveis, ou seja, os investimentos são viáveis, no horizonte de 10 anos, bem como apresentaram TIR superior ao custo de oportunidade, mostrando que é viável investir nesses projetos.

Portanto, o método de destoxificação com a utilização do fosfato monobicálcico produziu melhores resultados econômicos, possibilitando utilização de um método de destoxificação da torta de mamona economicamente viável, em contraposição à tecnologia utilizada tradicionalmente na destoxificação da torta de mamona, a autoclavagem, que, como verificado, apesar de ser possível sua viabilidade, requer altos investimentos, principalmente com a aquisição da autoclave. A utilização da torta de mamona não tratada na ração apresentou desempenho bioeconômico menos favorável quando comparado com a maioria dos métodos de destoxificação da torta de mamona.

\section{CONCLUSÃO}

A utilização da torta de mamona tratada com fosfato monobicálcico resultou em melhores indicadores econômico-financeiros na terminação de ovinos.

A compra de animais e a alimentação foram os itens mais representativos economicamente nas despesas de custeio para produção de peso corporal e de carcaça.

\section{AGRADECIMENTOS}

Os autores agradecem ao FUNDECl/Banco do Nordeste pelo financiamento deste projeto.

\section{REFERÊNCIAS}

AMARAL RM et al. 2011. Desempenho produtivo e econômico de cordeiros confinados abatidos com três espessuras de gordura. Revista Brasileira de Saúde e Produção Animal 12: 155-165.

ANANDAN S et al. 2005. Effect of different physical and chemical treatments on detoxification of ricin in castor cake. Animal Feed Science and Technology 120: 159-168.

ANDRADE IRA et al. 2011. Viabilidade econômica de ovinos terminados em sistema de confinamento alimentados com feno de capim-elefante utilizando farelo de soja como fonte protéica na ração. Revista Científica de Produção Animal 13: $150-155$.

AOAC. 1990. Association of Official Analytical Chemistry. Official methods of analysis. 15.ed. Arlington: AOAC International. 1117p.

ASLANI MR et al. 2007. Castor Bean (Ricinus communis) toxicosis in a sheep flock. Toxicosis 49: 400-406.

BARROS NN et al. 2005. Eficiência bioeconômica de cordeiros $F_{1}$ Dorper $x$ Santa Inês para produção de carne. Pesquisa Agropecuária Brasileira 40: 825-831.

BARROS CS et al. 2009. Resultado econômico da produção de ovinos para carne em pasto de azevém e confinamento. Acta Scientiarum Animal Sciences 31: 77-85.

BESERRA LT. 2010. Casca de mamona em dietas para ovinos de corte. Dissertação (Mestrado em Zootecnia). Fortaleza: UFC. 80p.

CÂNDIDO MJD et al. 2008. Reserva de forragem para a seca: produção e utilização de feno. 1.ed. Fortaleza: Imprensa 
Universitária. $64 \mathrm{p}$.

COSTA RG et al. 2008. Caracterização do sistema de produção caprino e ovino na região semi-árida do estado da Paraíba. Brasil. Archivos de Zootecnia 57: 195-205.

CUNHA MGG et al. 2008. Desempenho, digestibilidade aparente em ovinos confinados alimentados com dietas contendo níveis crescentes de caroço de algodão integral. Revista Brasileira de Zootecnia 37: 1103-1111.

FURTADO RN et al. 2012. Valor nutritivo de dietas contendo torta de mamona submetida a métodos alternativos de destoxificação para ovinos. Arquivo Brasileiro de Medicina Veterinária e Zootecnia 64: 155-162.

GOMES FHT et al. 2012. Características de carcaça em ovinos alimentados com rações contendo torta de mamona. Revista Brasileira de Saúde e Produção Animal 13: 283-295.

HOFFMAN R et al. 1987. Administração da empresa agrícola. 5.ed. São Paulo: Pioneira. 325p.

KABAT EA et al. 1947. A study of the purification and properties of ricin. Journal of Biological Chemistry 168: 629-639.

LEHNINGER AL et al. 1995. Princípios de Bioquímica. 2.ed. São Paulo: Sarvier. 840p.

NRC. 2007. National Research Council. Nutrient requeriments of small ruminants. 1.ed. Washington: National Academy Press. 362p.

OLIVEIRA AS et al. 2010. Nutrient digestibility, nitrogen metabolism and hepatic function of sheep fed diets containing solvent or expeller castorseed meal treated with calcium hydroxide. Animal Feed Science and Technology 158: 15-28.

PAIM TP et al. 2011. Estudo econômico da produção de cordeiros cruzados confinados abatidos em diferentes pesos. Ciência Animal Brasileira 12: 48-57.

POMPEU RCFF. 2009. Substituição do farelo de soja pela torta de mamona destoxificada em dietas para ovinos: valor nutritivo e desempenho bioeconômico. Tese (Doutorado em Zootecnia). Fortaleza: UFC. 101p.

SAS INSTITUTE. 2003. SAS system for Windows: Version 9.1. Cary.

VIEIRA MMM. 2009. Desempenho bioeconômico de ovinos alimentados com rações contendo farelo de mamona destoxificado. Dissertação (Mestrado em Zootecnia). Fortaleza: UFC. 85p. 